\title{
SALES LOSSES IN THE FIRST QUARTER OF THE COVID-19 PANDEMIC: EVIDENCE FROM CALIFORNIA ADMINISTRATIVE DATA
}

\author{
Robert W. Fairlie \\ Frank M. Fossen \\ Working Paper 28414 \\ http://www.nber.org/papers/w28414 \\ NATIONAL BUREAU OF ECONOMIC RESEARCH \\ 1050 Massachusetts Avenue \\ Cambridge, MA 02138 \\ January 2021
}

We would like to thank Isabel Guzman at the California Governor's Office of Business and Development, and Irena Asmundson at the California Department of Finance, for help with the data. The views expressed herein are those of the authors and do not necessarily reflect the views of the National Bureau of Economic Research.

NBER working papers are circulated for discussion and comment purposes. They have not been peer-reviewed or been subject to the review by the NBER Board of Directors that accompanies official NBER publications.

(C) 2021 by Robert W. Fairlie and Frank M. Fossen. All rights reserved. Short sections of text, not to exceed two paragraphs, may be quoted without explicit permission provided that full credit, including $\odot$ notice, is given to the source. 
Sales Losses in the First Quarter of the COVID-19 Pandemic:

Evidence from California Administrative Data

Robert W. Fairlie and Frank M. Fossen

NBER Working Paper No. 28414

January 2021

JEL No. H25,I18,L26

\begin{abstract}
$\underline{\text { ABSTRACT }}$
COVID-19 led to a massive shutdown of businesses in the second quarter of 2020. Estimates from the CPS, for example, indicate that the number of active business owners dropped by 22 percent from February to April 2020. In this descriptive research note, we provide the first analysis of losses in sales and revenues among the universe of businesses in California using administrative data from the California Department of Tax and Fee Administration. The losses in sales average 17 percent in the second quarter of 2020 relative to the second quarter of 2019 even though year-over-year sales typically grow by 3-4 percent. We find that sales losses were largest in businesses affected by mandatory lockdowns such as Accommodations, which lost 91 percent, whereas online sales grew by 180 percent. Losses also differed substantially across counties with large losses in San Francisco (50 percent) and Los Angeles (24 percent) whereas some counties experienced small gains in sales. Placing business types into different categories based on whether they were essential or non-essential (and thus subject to early lockdowns) and whether they have a moderate or high level of person-to-person contact, we find interesting correlations between sales losses and COVID-19 cases per capita across counties in California. The results suggest that local implementation and enforcement of lockdown restrictions and voluntary behavioral responses as reactions to the perceived local COVID-19 spread both played a role, but enforcement of mandatory restrictions may have had a larger impact on sales losses.
\end{abstract}

\author{
Robert W. Fairlie \\ Department of Economics \\ Engineering 2 Building \\ University of California at Santa Cruz \\ Santa Cruz, CA 95064 \\ and NBER \\ rfairlie@ucsc.edu \\ Frank M. Fossen \\ Department of Economics \\ University of Nevada, Reno \\ 1664 N. Virginia Street \\ Reno, NV 89557-0030 \\ ffossen@unr.edu
}




\section{Introduction}

The widespread closing of stores and businesses in the United States and around the world due to the coronavirus is unprecedented. Stores, factories and many other businesses have closed by policy mandate, downward demand shifts, health concerns, or other factors. Estimates from the CPS, for example, indicate that the number of active business owners in the United States plummeted from 15.0 million in February 2020 to 11.7 million in April 2020 and only partially rebounded by June (Fairlie 2020). ${ }^{1}$ By June losses were at 1.2 million. The shutdowns and reductions in work activity are likely to have resulted in substantial lost income for business owners and may result in permanent closures. ${ }^{2}$

In this descriptive paper, we provide the first analysis of sales losses among businesses using administrative data from the California Department of Tax and Fee Administration. We examine taxable sales by type of business and across counties within California. We find substantial losses in 2020 Q2 in total taxable sales in California. Although average year over year growth by quarter is normally roughly 3-4 percent, sales dropped by 17 percent from 2019 Q2 to 2020 Q2. Across industries, the losses were much more severe for those deemed "non-essential" or ones with substantial person-to-person contact. For example, Accommodations sales dropped by 92 percent, bars by 86 percent, and clothing stores by 52 percent. In contrast, however, online sales grew by 180 percent. Across counties in California, we find that counties that experienced more COVID-19 cases per capita suffered a greater percent decline in sales. This relationship was most pronounced for businesses affected by mandatory lockdowns, but also for businesses with high levels of person-to-person contact.

These findings contribute to the scant evidence on the effects of COVID-19 on the sales and revenues of small businesses. ${ }^{3}$

\footnotetext{
${ }^{1}$ Additional evidence of business shutdowns early in the pandemic is provided, for example, from the weekly U.S. Census Small Business Pulse Survey which indicates that roughly 50 percent of businesses report having a large negative effect from the COVID-19 pandemic (U.S. Census Bureau 2020; Bohn, Mejia and Lafortune 2020). Bartik et al. (2020) conducted a survey in late March of nearly 6,000 small businesses that were members of the Alignable Business Network. They find that 43 percent of businesses are temporarily closed, large reductions in employees, and that the majority of businesses have less than one month of cash on hand.

${ }^{2}$ Just prior to the pandemic when small business owners were asked what actions they would take if faced with a two-month revenue loss roughly half said they would use their own funds and 17 percent said they would close or sell the business (Mills et al. 2020).

${ }^{3}$ In California, 98 percent of business establishments with employees have less than 100 employees (U.S. Census Bureau 2018).
} 
Data from the transactions of financial accounts at JP Morgan Chase (JPMC) indicate that small business revenues dropped 30-50 percent at the end of March and early April and 40 percent into May (Farrell, Wheat and Mac 2020; Kim, Parker and Schoar 2020). In surveys conducted by the Kauffman Foundation, Desaii and Looze (2020) find that 60 percent of business owners reported lower sales in April and 50 percent of owners reported lower sales in May. The Opportunity Insights Economic Tracker reports small business revenue data from Womply and finds a drop of 50 percent in April from January and a rebound of only 30 percent since then. ${ }^{4}$ Bloom, Fletcher and Yeh (2021) partnered with a large payments technology company to collect survey data from 2,500 small businesses and find an average loss of 29 percent in sales in 2020 Q2. We build on these findings by analyzing data from the State of California that covers all sectors reporting taxable sales across the 58 counties in the state. ${ }^{5}$

The findings are potentially important for future targeting and oversight of government aid to preserve small businesses and the jobs they create. The results also have implications for discussions around what the federal government will do next (e.g. President Biden’s proposed \$1.9 trillion coronavirus stimulus package).

\section{Results}

The data used here are from the California Department of Tax and Fee Administration. We focus on taxable sales for all businesses in the state. In California taxable sales decreased substantially in the second quarter of 2020, which directly followed the social distancing restrictions imposed by the state. ${ }^{6}$ Total taxable sales in California were $\$ 152$ billion in 2020 Q2 which represents a drop of 17.5 percent from 2019 Q2. Typically year over year growth for the same quarter is between 3 to 4 percent (see Figure 1). The sharp decline in sales was not due to a loss in the number

\footnotetext{
${ }^{4}$ See https://tracktherecovery.org/. Womply aggregates data from several credit card processors to analyze for small businesses. The data are distributed across sectors for which credit card use is common and focus on small businesses, thus comprising a larger share of food services, professional services, and other services.

${ }^{5}$ The findings also contribute to the broader literature on the general relationship between recessions and entrepreneurship. The evidence is surprisingly mixed with many previous studies showing positive relationships, negative relationships, and zero relationships (Parker 2018).

${ }^{6}$ On March 11, 2020, the World Health Organization (WHO) declared COVID-19 a pandemic. On March 16, the San Francisco Bay Area imposed the first shelter-in-place restrictions in the country followed by the State of California on March 19. New York State followed the next day. By early April most states imposed social distancing restrictions.
} 
of sales permits which experienced growth of 1 percent from 2019 Q2 to 2020 Q2. Average sales per business permit dropped by 18.3 percent to $\$ 123,237$ in 2020 Q2.

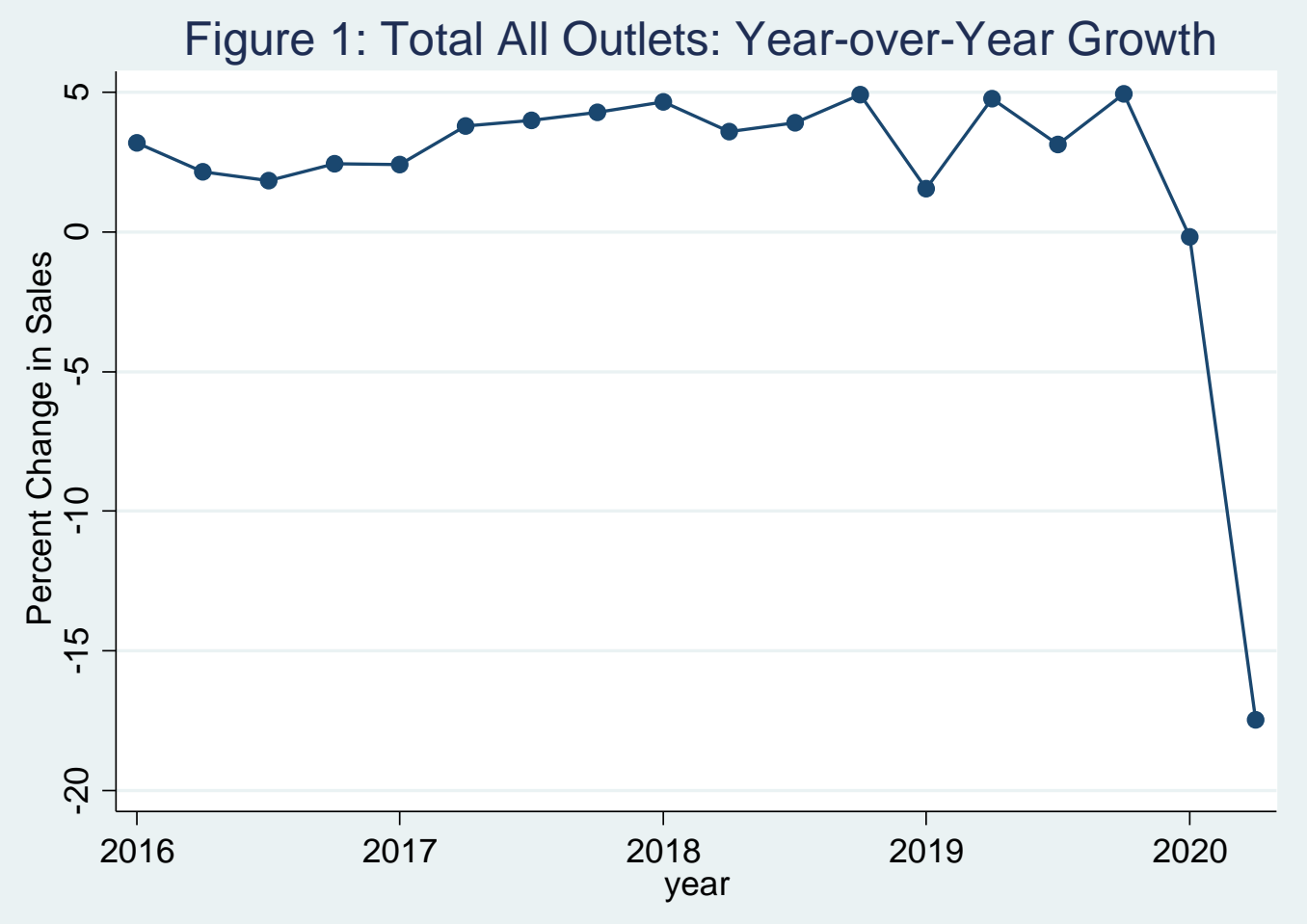

\section{Event Study Results}

We estimate a simple event-study regression in which we adjust for a time trend and allow for seasonal (quarter) fixed effects. The results do not change from the comparison of 2019 Q2 to 2020 Q2 and adding an average growth rate over the time period. We find that total taxable sales losses are predicted to be \$37.9 billion or a 20.5 percent drop from 2019 Q2 levels. Using a quadratic time trend instead of a linear time trend results in a slightly larger loss in total sales from COVID-19. We focus the remaining analysis on 2019 Q2 to 2020 Q2 comparisons for simplicity and clarity.

\subsection{Losses across Business Types (Categories, Types, Subtypes)}

To slow the spread of COVID-19 governments enforced social distancing restrictions that shut down businesses in jobs and industries deemed "non-essential." Less drastic restrictions were also imposed on "essential” businesses, such as capacity limitations for grocery stores. Health concerns 
also dissuaded customers from visiting stores that had person-to-person contact. Finally, the ability to telecommute in jobs allowed certain businesses or at least certain jobs in those businesses to continue to operate.

We investigate losses across business types used by the Department of Tax and Fee Administration. Table 1 report the percent change in sales from 2019Q2 to 2020Q2 and sales levels in 2020Q2 for aggregated business types. Starting with stores that were mostly considered "nonessential” and have person-to-person contact we find major losses. Clothing and Clothing Accessories Stores lost 54.5 percent from the second quarter of 2019 to the second quarter of 2020.

Table 1: California Taxable Sales Losses by Business Types

\begin{tabular}{|c|c|c|c|}
\hline Business Type & $\begin{array}{l}\text { Percent } \\
\text { Change } \\
2019 Q 2 \text { to } \\
2020 Q 2\end{array}$ & $\begin{array}{c}\text { Taxable } \\
\text { Transactions } \\
\text { Amount }\end{array}$ & $\begin{array}{c}\text { Percent of } \\
\text { Total Tax }\end{array}$ \\
\hline Total All Outlets & -17 & $152,362,296,481$ & 100.0 \\
\hline Total Retail and Food Services & -17 & $105,528,311,167$ & 69.3 \\
\hline Motor Vehicle and Parts Dealers & -15 & $19,294,245,937$ & 12.7 \\
\hline Furniture and Home Furnishings Stores & -18 & $2,625,229,637$ & 1.7 \\
\hline Electronics and Appliance Stores & -14 & $3,663,719,124$ & 2.4 \\
\hline Building Material and Garden Equipment & 12 & $12,248,068,380$ & 8.0 \\
\hline Food and Beverage Stores & 2 & $7,584,295,812$ & 5.0 \\
\hline Health and Personal Care Stores & -11 & $3,414,123,225$ & 2.2 \\
\hline Gasoline Stations & -47 & $7,737,896,946$ & 5.1 \\
\hline Clothing and Clothing Accessories Stores & -54 & $4,744,372,982$ & 3.1 \\
\hline Sporting Goods, Hobby, Musical Instrume & -20 & $2,010,965,666$ & 1.3 \\
\hline General Merchandise Stores & -10 & $12,522,013,242$ & 8.2 \\
\hline Miscellaneous Store Retailers & -17 & $4,418,659,674$ & 2.9 \\
\hline Food Services and Drinking Places & -47 & $11,991,170,465$ & 7.9 \\
\hline Total All Other Outlets & -19 & $46,833,985,314$ & 30.7 \\
\hline
\end{tabular}

Source: Administrative data from the California Department of Tax and Fee Administration.

Food Services and Drinking Places were not shut down, but faced restrictions in terms of switching to takeout and delivery service only and then later adding outside dining service. These restrictions and concerns over health led to a major drop in demand. Sales at restaurants, bars, and other eating establishments dropped 47.4 percent from 2019 Q2 to 2020 Q2. In contrast, this 
business type category was experiencing year over year growth of 3-6 percent prior to the pandemic. Gasoline was deemed essential but as workers stayed at home and business travel was mostly shut down gasoline stations lost substantial revenue. From the second quarter 2019 to the second quarter 2020 sales dropped by 47.0 percent. Larger purchases and ones with more flexibility in timing of purchases experienced large, but smaller drops in taxable sales. Home Furnishings and Appliance Stores dropped 15.5 percent over the year. Similarly, Motor Vehicle and Parts Dealers dropped by 14.8 percent.

Not all businesses experienced large losses. Businesses that were deemed "essential" were not forced to close and remained open during the first three months of the pandemic (i.e. second quarter 2020). Food and Beverage Stores experienced an increase of 1.7 percent but the growth rate was lower than average year of year growth in sales. Building Material and Garden Equipment grew by 12.1 percent which likely reflects the many home and garden repair and improvement projects started by home owners with more time on their hands during the pandemic.

“General Merchandise Stores” capture both essential and non-essential goods so were often open during the pandemic. They experienced a drop of 9.8 percent from 2019 Q2 to 2020 Q2. All other outlets experienced a drop of 19.4 percent.

Combing all business types, All Outlets experienced a drop of 17.5 percent. Total Retail and Food Services dropped by a similar amount, 16.6 percent.

In Figure 2 we report losses for selected disaggregated business types for large losses and large gains in 2020 Q2 (see Appendix Table 1 for all business types). Drilling down by detailed business type reveals some extremely large losses for specific sectors. The Accommodation subsector had the largest loss at 91 percent, followed by the 86 percent drop in taxable sales at Drinking Places-Alcohol, and the 83 percent drop at Arts, Entertainment and Recreation places. Full-service restaurants, which were often shut down or switched to take out, also did not fare well with sales losses of 61 percent. Small shops selling Gifts and Souvenirs, Clothing, or Books also experienced large losses in the second quarter of 2020. All of these businesses are characterized as by being “non-essential” and/or suffered from reduced demand because of high levels of personto-person contact. 


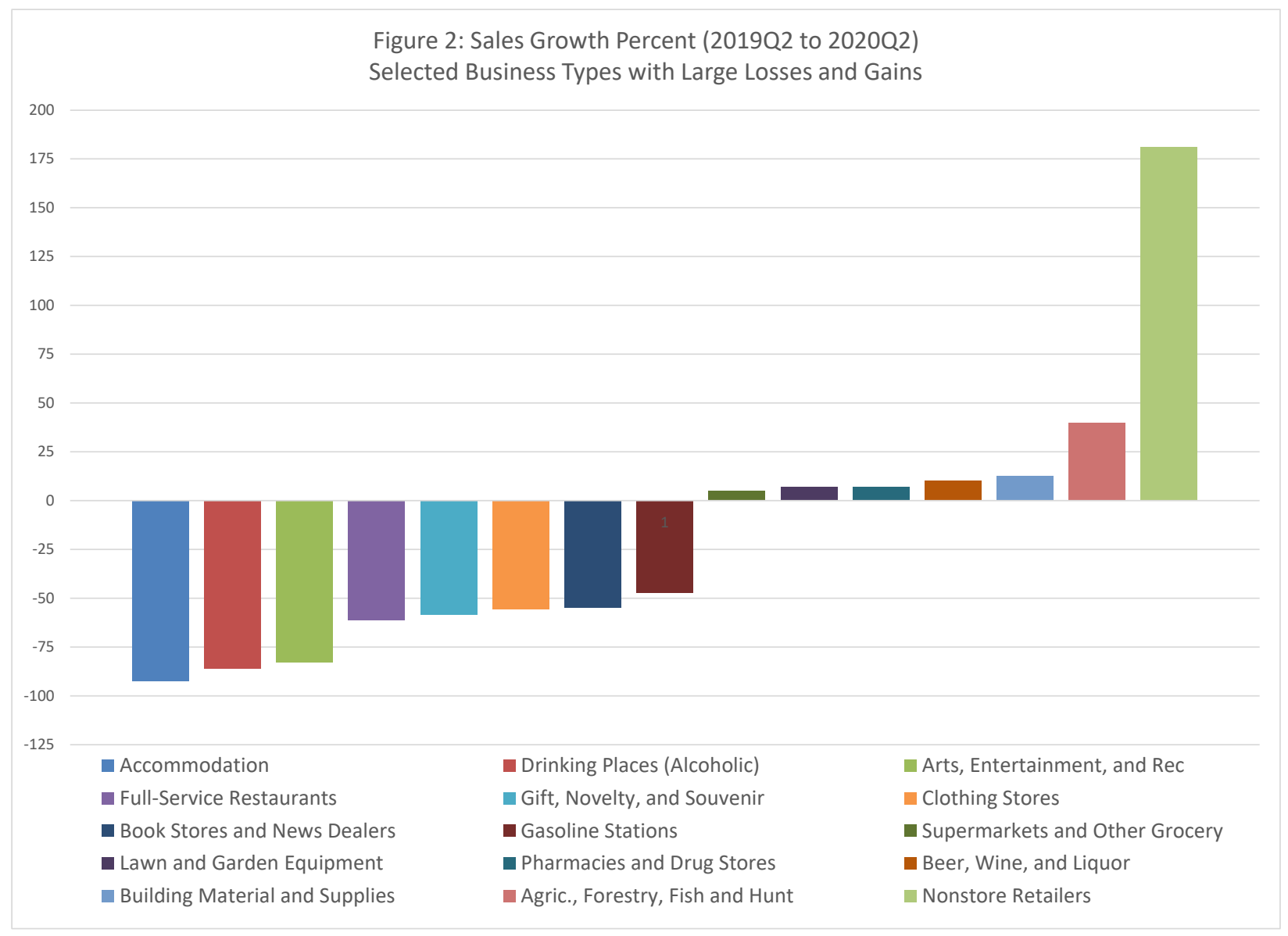

On the other end of the spectrum, some business types did extremely well. The shift by consumers to online purchases bolstered the sector "Nonstore Sales" into astonishing positive growth of 181 percent. The sectors of Agriculture, Building Materials, Pharmacies, Garden Centers, Supermarkets, and even Liquor Stores were deemed “essential” and experienced positive sales growth from 2019 Q2 to 2020 Q2. Although Supermarkets experienced growth of 5 percent in 2020 Q2 the shutdown and avoidance of many restaurants and previous annual growth of roughly 2 percent suggested perhaps larger potential growth. ${ }^{7}$ Interestingly, 2020 Q1 experienced growth of over 10 percent over 2019 Q1 which might reflect some panic buying of food and supplies when concerns over the pandemic first hit. Concerns over health and changing restrictions on the shopping experience then might have tempered demand somewhat for visiting supermarkets in 2020 Q2.

\footnotetext{
${ }^{7}$ Note that most grocery items are exempt from sales tax in California. Taxable items include hot prepared food products, carbonated beverages, effervescent bottled water, wine, and spirits, for example.
} 
Overall, the patterns of sales losses and growth indicate a shift from in-store purchases to online purchases, and from restaurants to grocery stores. Whether an industry was deemed essential vs. non-essential had a major impact on whether sales growth was negative or positive in the second quarter of 2020. Finally, consumers avoided business subsectors in which there was a lot of person-to-person contact because of health concerns over the coronavirus.

\subsection{Losses across Counties}

California has a diverse set of counties ranging from large, densely populated counties such as Los Angeles and San Francisco to very small rural counties in the mountains such as Alpine and Shasta counties. Related to population density COVID-19 cases per capita differed substantially across counties. Table 2 reports taxable sales losses by county for all outlets and cumulative confirmed COVID-19 cases per capital by May 15, 2020. Businesses in San Francisco County experienced one of the largest sales losses across all counties, dropping by 50 percent from 2019 Q2 to 2020 Q2. Los Angeles County experienced a drop in taxable sales of 24 percent, and San Diego County experienced a drop in taxable sales of 19 percent. In contrast, several small counties actually experienced positive growth in taxable sales from 2019 Q2 to 2020 Q2. 
Table 2: California Taxable Sales Losses by County

\begin{tabular}{|c|c|c|c|c|c|c|c|}
\hline County & $\begin{array}{c}\text { Change } \\
\text { 2019Q2 } \\
\text { to } \\
2020 Q 2\end{array}$ & $\begin{array}{c}\text { Taxable } \\
\text { Transactions } \\
\text { Amt. M\$ }\end{array}$ & $\begin{array}{l}\text { Cum. } \\
\text { COVID-19 } \\
\text { Cases per } \\
1000 \text { Inh. }\end{array}$ & County & $\begin{array}{c}\text { Change } \\
\text { 2019Q2 } \\
\text { to } \\
2020 Q 2\end{array}$ & $\begin{array}{c}\text { Taxable } \\
\text { Transactions } \\
\text { Amt. M\$ }\end{array}$ & $\begin{array}{l}\text { Cum. } \\
\text { COVID-19 } \\
\text { Cases per } \\
1000 \text { Inh. }\end{array}$ \\
\hline LOS ANGELES & $-24 \%$ & $32,702.3$ & 3.59 & IMPERIAL & $-9 \%$ & 614.9 & 4.36 \\
\hline ORANGE & $-25 \%$ & $13,242.8$ & 1.30 & EL DORADO & $-6 \%$ & 591.6 & 0.34 \\
\hline SAN DIEGO & $-19 \%$ & $12,388.5$ & 1.67 & KINGS & $15 \%$ & 535.3 & 2.48 \\
\hline SANTA CLARA & $-13 \%$ & $10,061.4$ & 1.25 & HUMBOLDT & $-2 \%$ & 513.4 & 0.53 \\
\hline SAN BERNARDINO & $-8 \%$ & $9,633.8$ & 1.55 & SUTTER & $0 \%$ & 489.2 & 0.39 \\
\hline RIVERSIDE & $-7 \%$ & $9,554.2$ & 2.36 & MADERA & $2 \%$ & 475.3 & 0.45 \\
\hline ALAMEDA & $-26 \%$ & $6,601.6$ & 1.40 & MENDOCINO & $-6 \%$ & 391.8 & 0.15 \\
\hline SACRAMENTO & $-7 \%$ & $6,339.9$ & 0.80 & NEVADA & $2 \%$ & 377.4 & 0.41 \\
\hline FRESNO & $-3 \%$ & $4,011.2$ & 1.18 & TEHAMA & $-11 \%$ & 234.6 & 0.03 \\
\hline CONTRA COSTA & $-16 \%$ & $3,836.7$ & 0.97 & TUOLUMNE & $3 \%$ & 204.0 & 0.04 \\
\hline SAN JOAQUIN & $-1 \%$ & $3,646.0$ & 0.90 & SAN BENITO & $-1 \%$ & 187.6 & 1.01 \\
\hline KERN & $-9 \%$ & $3,642.2$ & 1.62 & LAKE & $8 \%$ & 183.5 & 0.12 \\
\hline SAN MATEO & $-31 \%$ & $3,147.7$ & 2.06 & YUBA & $5 \%$ & 177.9 & 0.33 \\
\hline VENTURA & $-16 \%$ & $3,123.6$ & 0.90 & SISKIYOU & $10 \%$ & 162.5 & 0.11 \\
\hline SAN FRANCISCO & $-50 \%$ & $2,648.4$ & 2.33 & COLUSA & $6 \%$ & 141.6 & 0.14 \\
\hline TULARE & $28 \%$ & $2,541.1$ & 2.91 & GLENN & $-2 \%$ & 136.3 & 0.32 \\
\hline STANISLAUS & $-6 \%$ & $2,324.6$ & 1.01 & AMADOR & $-4 \%$ & 122.6 & 0.24 \\
\hline PLACER & $-17 \%$ & $2,229.3$ & 0.46 & CALAVERAS & $7 \%$ & 118.8 & 0.29 \\
\hline SONOMA & $-16 \%$ & $2,144.6$ & 0.73 & LASSEN & $14 \%$ & 81.1 & 0.00 \\
\hline SOLANO & $-13 \%$ & $1,859.8$ & 0.93 & INYO & $-24 \%$ & 72.7 & 1.05 \\
\hline SANTA BARBARA & $-18 \%$ & $1,593.2$ & 3.16 & DEL NORTE & $7 \%$ & 67.1 & 0.15 \\
\hline MONTEREY & $-22 \%$ & $1,524.2$ & 0.88 & PLUMAS & $12 \%$ & 65.6 & 0.21 \\
\hline SAN LUIS OBISPO & $-15 \%$ & $1,229.1$ & 0.85 & MONO & $-31 \%$ & 48.1 & 2.33 \\
\hline MARIN & $-25 \%$ & $1,059.4$ & 1.10 & TRINITY & $27 \%$ & 37.1 & 0.08 \\
\hline YOLO & $-12 \%$ & $1,047.1$ & 0.85 & MARIPOSA & $-41 \%$ & 36.1 & 0.86 \\
\hline BUTTE & $-6 \%$ & 927.0 & 0.10 & MODOC & $5 \%$ & 25.0 & 0.00 \\
\hline SANTA CRUZ & $-17 \%$ & 857.1 & 0.54 & SIERRA & $-63 \%$ & 4.6 & 0.00 \\
\hline SHASTA & $-5 \%$ & 848.3 & 0.18 & ALPINE & $-14 \%$ & 3.8 & 1.75 \\
\hline MERCED & $-8 \%$ & 819.3 & 0.74 & CA Total & $-17 \%$ & $152,351.1$ & 1.97 \\
\hline NAPA & $-31 \%$ & 667.2 & 0.59 & & & & \\
\hline
\end{tabular}

Note: Cumulative COVID-19 cases are confirmed cases per 1000 inhabitants by May 15, 2020.

Source: Administrative data from the California Department of Tax and Fee Administration and USAFacts.

\subsection{COVID-19 Cases and Sales Losses by County}

In this section, we analyze how the changes in taxable sales were correlated with coronavirus cases at the county level. We obtain confirmed COVID-19 cases by county and day from USAFacts (2020) and use cumulative cases by May 15, 2020 (the midpoint in the second quarter) per capita. ${ }^{8}$ Of course, testing for COVID-19 was often not readily available in the second quarter of 2020, and availability and uptake of testing may have varied across counties. However, decisions of consumers and producers as well as decisions of policymakers about the implementation and enforcement of lockdowns were based on the same testing data, which were widely reported in the

\footnotetext{
${ }^{8}$ County population numbers are from the U.S. Census Bureau.
} 
media, including the local media. Therefore, our analysis is informative about the effects of the perceived local spread of COVID-19.

Figure 3 provides a scatter plot relating the growth rate in taxable sales across all business types between the second quarter in 2019 and the second quarter in 2020 to the cumulative number of COVID-19 cases per capita by May 15, 2020, in each of the 58 counties in California. The data indicate a clear negative relationship. A bivariate regression line is also shown; the slope coefficient is -40.06 with a standard error of 22.48, indicating that an additional known COVID19 case per 1000 inhabitants in a county was associated with an additional decline in taxable sales by 4 percentage points. ${ }^{9}$

Figure 3: Taxable Sales Losses by County for All Outlets

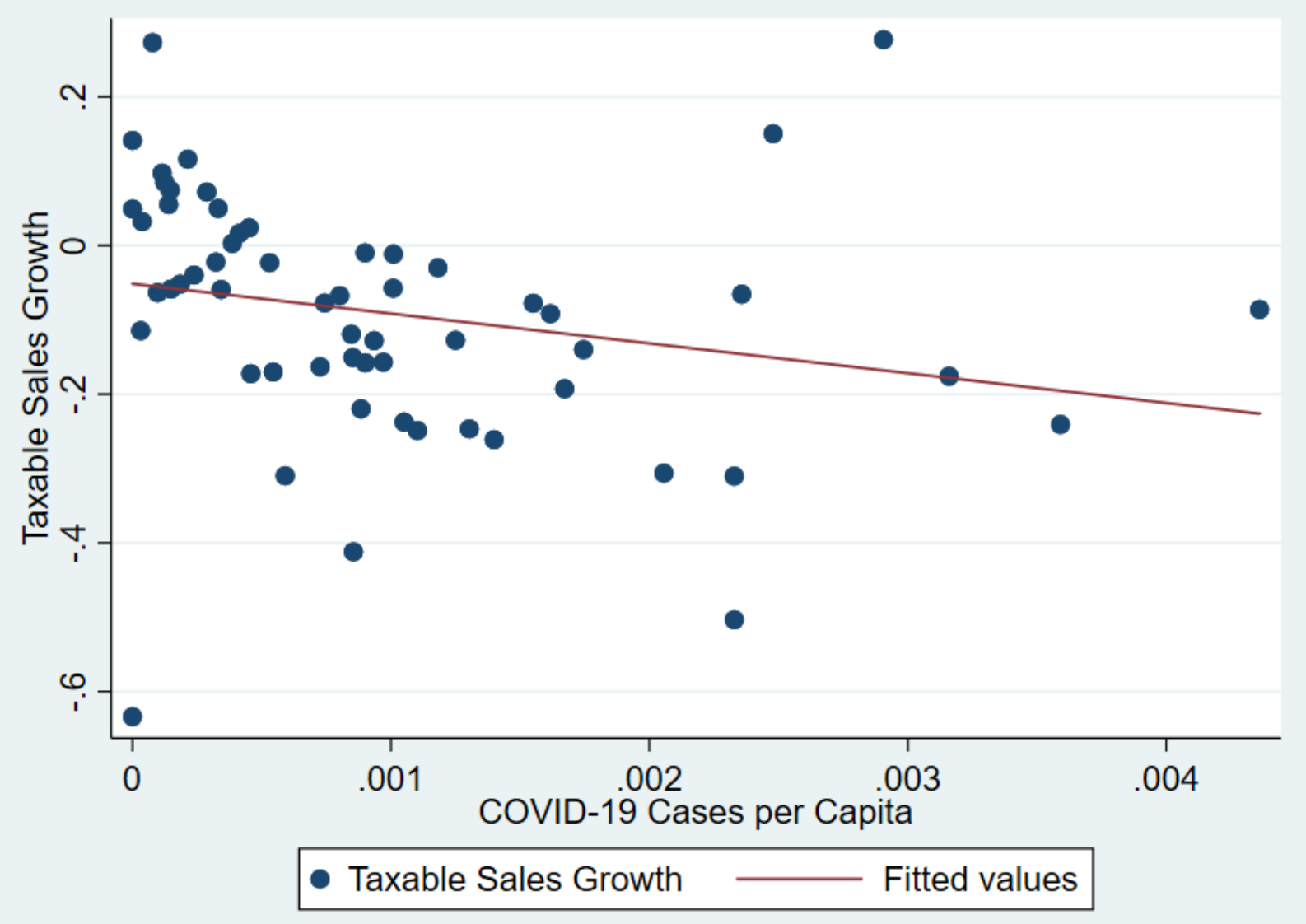

Notes: Each dot in the scatter plot represents one county in California. The taxable sales growth rate is the relative change between 2019 Q2 and 2020 Q2 for all outlets. COVID-19 cases are the cumulative confirmed cases per capita in the county by May 15, 2020. A linear bivariate regression line is also shown.

${ }^{9}$ Weighting the regression by the population size of the counties does not change the picture (see Figure B1 in Appendix B), the slope coefficient (std. err.) becomes -36.77 (0.0148). 
From a policy perspective, it is important to understand how much mandatory lockdown restrictions were binding. Would consumers have avoided spending or producers shut their businesses due to fear of contagion even without government intervention? A comparison across different business types sheds some light on these questions. Table 3 classifies exemplary business types by whether they were deemed non-essential and therefore subject to strong lockdown restrictions and by the possibility to maintain social distance from other people (workers or customers). For example, garden equipment and clothing shops may have comparable opportunities for maintaining social distance, but the former business type was exempt from stricter lockdown restrictions because it was considered essential. Therefore, if we find a stronger correlation between known COVID-19 cases and sales losses for clothing than gardening shops at the county level, this may be attributable to the imposition and enforcement of lockdown restrictions, which can be expected to be stricter in counties with more COVID-19 cases per capita. In contrast, both clothing shops and restaurants (food services and drinking places) were classified as non-essential and therefore subject to similar lockdown restrictions in California in the second quarter of 2020, but social distancing may be easier in clothing shops; therefore, if we find different strengths of correlation between COVID-19 cases and sales losses in these types of businesses, this may be attributable to voluntary behavior of customers or sellers due to caution and fear of contagion. ${ }^{10}$

Table 3: Potential Exposure of Business Types to the Pandemic

“Essential” (no lockdown) "Non-essential” (subject to lockdown)

\begin{tabular}{lll}
\hline Moderate person-to-person contact & $\begin{array}{l}\text { Building Material and } \\
\text { Garden Equipment; } \\
\text { Gasoline Stations }\end{array}$ & $\begin{array}{l}\text { Clothing and Clothing } \\
\text { Accessories Stores }\end{array}$ \\
High person-to-person contact & Food and Beverage Stores & $\begin{array}{l}\text { Food Services and } \\
\text { Drinking Places }\end{array}$ \\
\hline
\end{tabular}

\footnotetext{
${ }^{10}$ We classify food and beverage stores into the high person-to-person contact category due to the often comparably high density of customers and employees in and around these stores. Keep in mind that most grocery items are exempt from sales tax in California, see footnote 7.
} 
Motivated by these considerations, we compare scatter plots with unweighted regression lines for the business types mentioned in Table 3. They appear in Figures 4-7. ${ }^{11}$ All of these plots reveal negative relationships between local known COVID-19 cases and sales growth. The finding that this negative relationship is not only observed for business types that are subject to strict lockdown restrictions, but also for so-called essential business types such as garden equipment stores and grocery stores, indicates that at least some of the drop in sales is driven by a voluntary change of behavior by consumers and producers out of caution when the local spread of COVID19 seemed high, and potentially also by larger drops in income in these regions. However, the negative slopes of the relationships are steeper for non-essential businesses that were subject to strict lockdown restrictions, indicating that the imposition and enforcement of lockdown restrictions also played an important role.

We begin by contrasting two business types which seem comparable in terms of social distancing possibilities: building material and garden equipment stores, which were considered essential businesses, in Figure 4, and clothing stores, which were non-essential, in Figure 5. The impact of local known COVID-19 cases on sales was larger for clothing stores. While sales grew on average for building materials and gardening stores, they shrank on average for clothing stores, presumably due to the stricter lockdown restrictions for the latter business type. In addition to the level difference, the negative correlation of sales growth with local known COVID-19 cases is much stronger for clothing stores, with a regression slope coefficient (std. err.) of -169.9 (38.57), in comparison to building material and gardening stores with a slope (std. err.) of -40.72 (19.63). ${ }^{12}$ This suggests that stronger local enforcement of lockdown restrictions in the case of clothing stores when local COVID-19 spread was high had a larger effect than voluntary reactions of customers and sellers in the case of building materials and gardening stores.

\footnotetext{
${ }^{11}$ Appendix Figure B2 additionally contains a plot for gasoline stations, a second business type in the group of essential businesses with moderate person-to-person interaction.

${ }^{12}$ Gasoline stations, which were also essential and have a medium level of person-to-person interaction like building material and gardening stores, exhibit a similar slope coefficient (std. err.) of -41.99 (17.38), see Figure B2 in Appendix B. However, there is a large level difference, with gasoline stations suffering large declines in sales on average, presumably due to lower demand for gasoline as people worked from home.
} 
Figure 4: Taxable Sales Losses by County for Building Materials and Garden Equipment

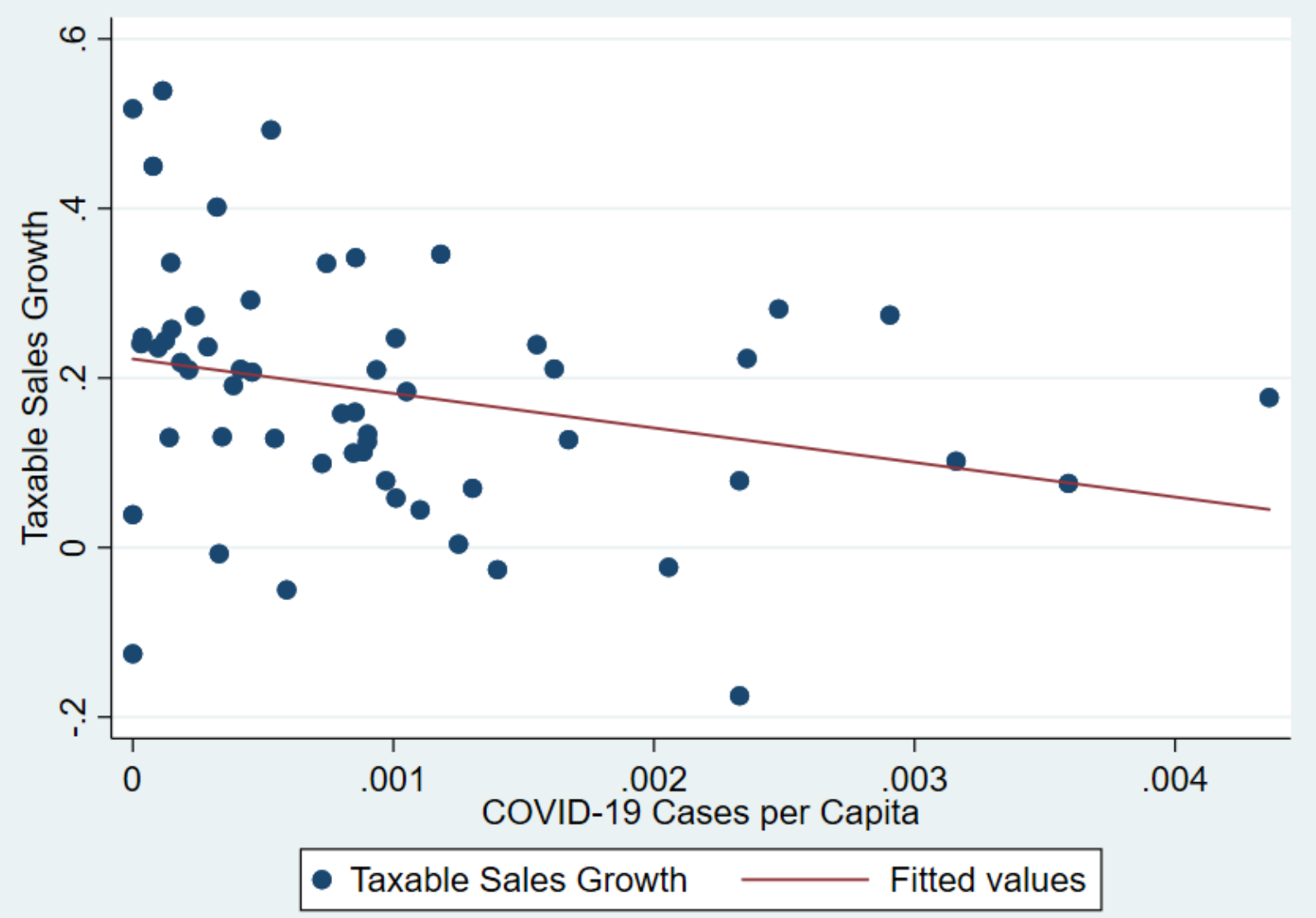

Notes: Each dot in the scatter plot represents one county in California. The taxable sales growth rate is the relative change between 2019 Q2 and 2020 Q2 for building material and garden equipment stores. COVID-19 cases are the cumulative confirmed cases per capita in the county by May 15th, 2020. A linear bivariate regression line is also shown. 
Figure 5: Taxable Sales Losses by County for Clothing and Clothing Accessories Stores

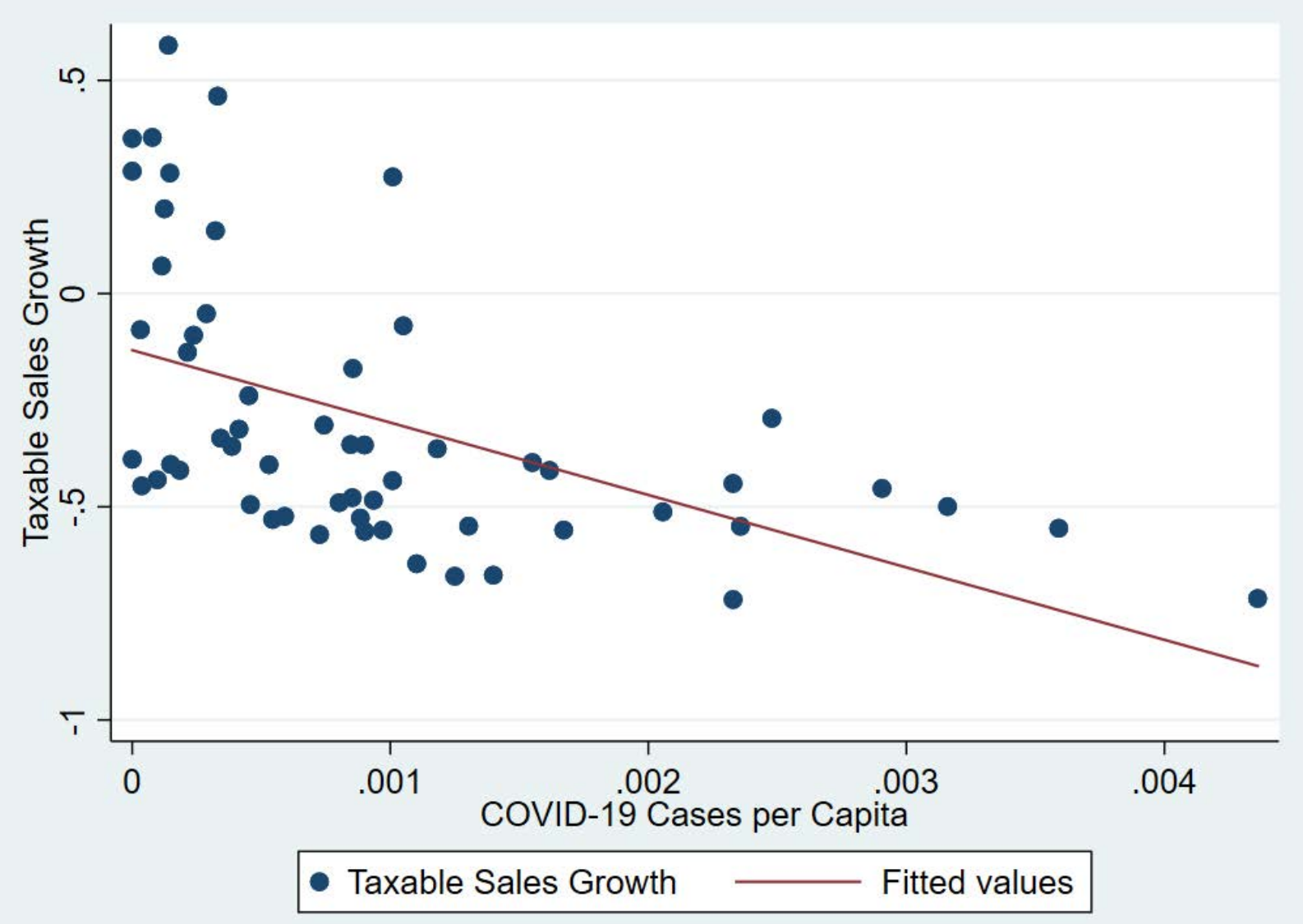

Notes: Each dot in the scatter plot represents one county in California. The taxable sales growth rate is the relative change between 2019 Q2 and 2020 Q2 for clothing and clothing accessories stores. COVID-19 cases are the cumulative confirmed cases per capita in the county by May 15th, 2020. A linear bivariate regression line is also shown.

When comparing two business types that were both considered non-essential, clothing stores on the one hand and food services and drinking places (in Figure 6) on the other, one might have expected a larger impact of COVID-19 on restaurants and bars, because social distancing in these businesses seems harder than in clothing stores; both business types were generally allowed to offer at least (curbside) pickup and delivery. However, the negative correlation between sales growth and known COVID-19 cases is actually weaker for restaurants and bars, with a slope (std. err.) of -45.21 (21.17). This is another indication suggesting that voluntary behavior change as a reaction to local COVID-19 cases was not the main driver of industry and county differences in sales declines. 
Figure 6: Taxable Sales Losses by County for Food Services and Drinking Places

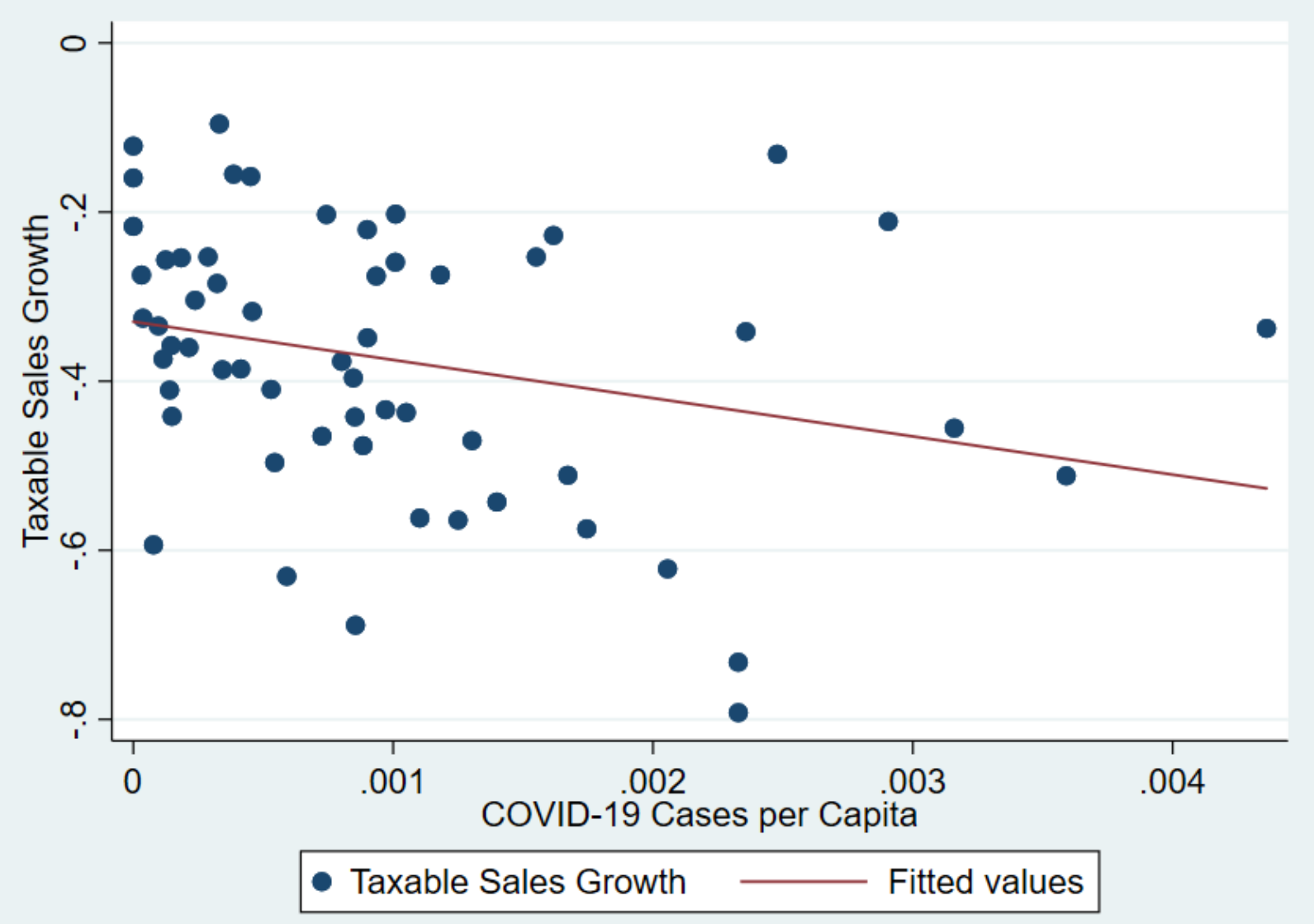

Notes: Each dot in the scatter plot represents one county in California. The taxable sales growth rate is the relative change between 2019 Q2 and 2020 Q2 for food services and drinking places. COVID-19 cases are the cumulative confirmed cases per capita in the county by May 15th, 2020. A linear bivariate regression line is also shown.

Finally, food and beverage stores (Figure 7) experienced an increase in sales on average, in contrast to food services and drinking places, which is likely due to the fact that grocery stores were deemed essential and subject to fewer lockdown restrictions. The negative association between sales growth and COVID-19 cases is similar in both cases, however: the regression coefficient (std. err.) for food and beverage stores is -58.27 (16.70). When weighting the regressions by county population, the correlation is more negative for restaurants and bars with a slope (std. err.) of $-41.08(0.0168)$ than for food and beverage stores with -16.98 (0.00883), suggesting that the local enforcement of lockdown restrictions was important again. The unweighted point estimate of the slope is steeper for grocery stores than for building material and gardening stores, which were also considered essential. This suggests that voluntary reactions to 
the number of known local COVID-19 infections in case of the often more crowded grocery stores played a role, but not a very large one.

Figure 7: Taxable Sales Losses by County for Food and Beverage Stores

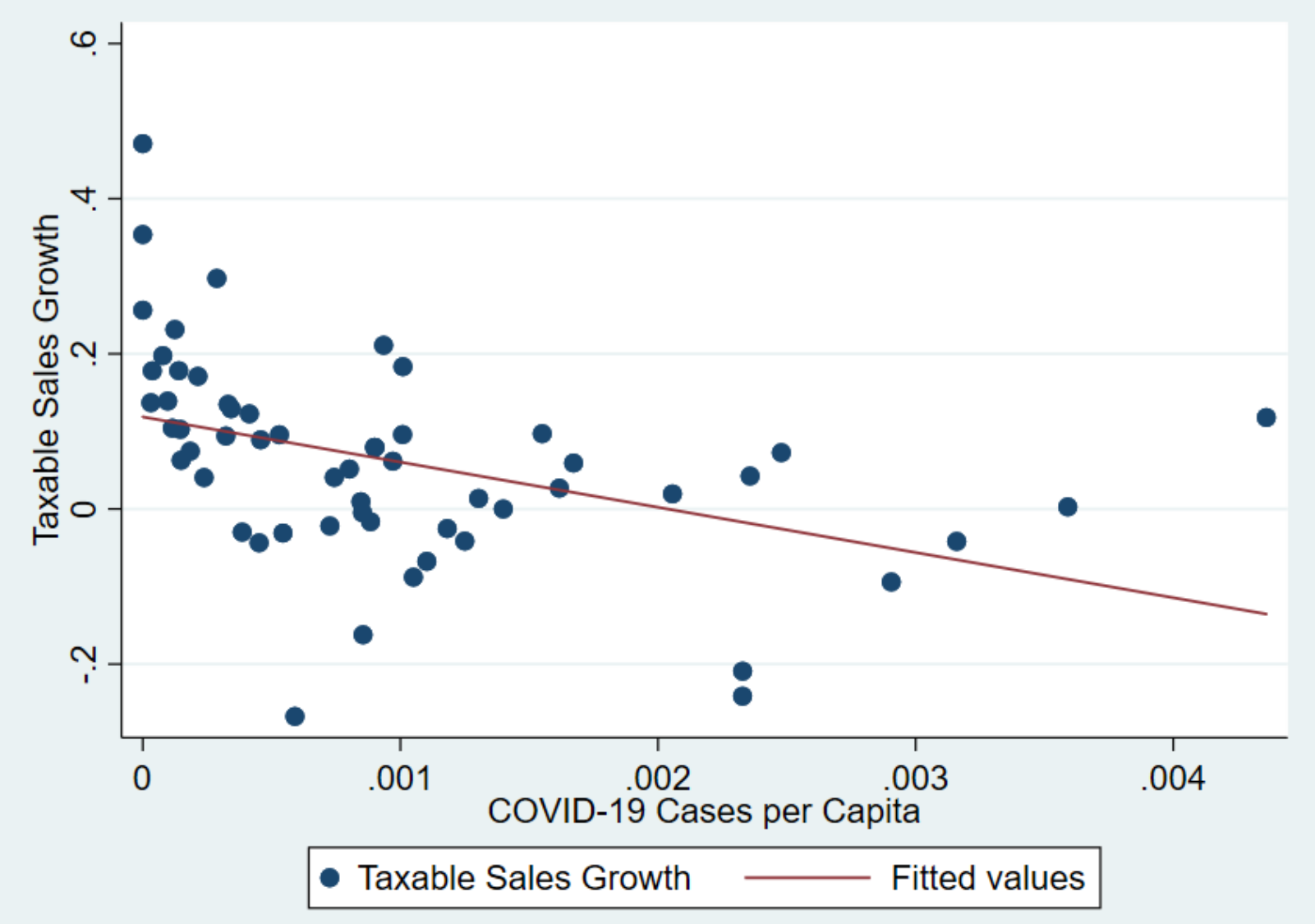

Notes: Each dot in the scatter plot represents one county in California. The taxable sales growth rate is the relative change between 2019 Q2 and 2020 Q2 for food and beverage stores. COVID-19 cases are the cumulative confirmed cases per capita in the county by May 15th, 2020. A linear bivariate regression line is also shown.

\section{Conclusions}

Although it is well known that COVID-19 led to a massive shutdown of businesses in the second quarter of 2020, surprisingly little is known about actual sales and revenues losses in the early stages of the pandemic. Using administrative data from the California Department of Tax and Fee Administration, we provide new evidence on sales losses among the universe of businesses by detailed business types and locations. Normal year-over-year growth in taxable sales is 3-4 percent, 
but losses in sales were 17 percent in the second quarter of 2020 relative to the second quarter of 2019. Sales losses were largest in businesses affected by mandatory lockdowns such as Accommodations at 91 percent. But, other types of businesses experienced large gains, such as online sales, which grew by 180 percent as consumers substituted away from in-store purchases.

Placing business types into different categories based on whether they are "essential" or "non-essential" (and thus subject to early lockdowns) and whether they have a moderate or highlevel of person-to-person contact, we find interesting correlations between sales losses and COVID-19 cases per capita across counties in California. The findings across these different classifications reveals that local implementation and enforcement of lockdown restrictions and voluntary behavioral responses as reactions to the perceived local COVID-19 spread both played a role, but enforcement of mandatory restrictions may have had a larger impact on sales losses.

The large losses in sales in the second quarter of 2020 for so many different types of business but especially those shut down through mandatory restrictions are worrisome for the longer-term survival of small, local businesses throughout the country. Although larger stores and chains with a strong online presence may survive, many small businesses will not have the resources to weather prolonged closures, continued reduced demand from health concerns, and a more comprehensive recession. Just prior to the pandemic when small business owners were asked what actions they would take if faced with a two-month revenue loss, 17 percent said they would close or sell the business (Mills et al. 2020). Estimates from the weekly U.S. Census Small Business Pulse Survey indicate that only 15-20 percent of businesses have enough cash on hand to cover 3 months of operations (U.S. Census Bureau 2020; Bohn, Mejia and Lafortune 2020). The government is considering future rounds of funds for the PPP program, and private foundations and companies are promising to help. Can these programs help small businesses survive the setbacks and shutdowns due to the coronavirus pandemic, or will more assistance be needed? Furthermore, will an added shift in consumer behavior away from large online retailers towards small businesses to fight longer-term trends be needed? States have promoted shopping local (e.g. California’s \#ShopSafeShopLocal) but can this counteract these trends? In the end, getting the latest surge in the virus in check and the roll out of vaccines to lift restrictions and restore customer, owner and employee confidence in health safety is likely the first real step to a full recovery for small businesses. 


\section{References}

Bartik, Alexander W., Zoe B. Cullen, Edward L. Glaeser, Michael Luca, Christopher T. Stanton, and Adi Sunderam. 2020. "The Targeting and Impact of Paycheck Protection Program Loans to Small Businesses,” National Bureau of Economic Research Working Paper No. w27623.

Bloom, Nicholas, Robert S. Fletcher, and Ethan Yeh. 2021. “The Impact of COVID-19 on US Firms” NBER Working Paper No. w28314.

Bohn, Sarah, Marisol Cuellar Mejia, and Julien Lafortune. 2020. “The Economic Toll of COVID-19 on Small Business,” Public Policy Institute of California.

Desai, Sameeksha, and Jessica Looze. 2020. "Business Owner Perceptions of COVID-19 Effects on the Business: Preliminary Findings,” Trends in Entrepreneurship, No. 10. Kauffman Foundation.

Farrell, Diana, Chris Wheat and Chi Mac. 2020. "Small Business Financial Outcomes during the Onset of COVID-19,” JPMorgan Chase \& Co. Institute Report.

Fairlie, Robert. 2020. “The Impact of COVID-19 on Small Business Owners: Evidence from the First Three Months after Widespread Social-distancing Restrictions,” Journal of Economics \& Management Strategy 29(4): 727-740.

Kim, Olivia S., Jonathan A. Parker and Antoinette Schoar. 2020. "Revenue Collapses and the Consumption of Small Business Owners in the Early Stages of the COVID-19 Pandemic," NBER Working Paper No. w28151.

Mills, Claire Kramer, Jessica Battisto, Mels de Zeeuw, Scott Lieberman, and Ann Marie Wiersch. 2020. Small Business Credit Survey, Federal Reserve Banks.

Parker, Simon C. 2018. The Economics of Entrepreneurship. Cambridge University Press

USAFacts. 2020. https://usafacts.org/visualizations/coronavirus-covid-19-spread-map/.

U.S. Census Bureau. 2018. “County Business Patterns Tables 2018”

https://www.census.gov/programs-surveys/cbp/data/tables.html

U.S. Census Bureau. 2020. “Small Business Pulse Survey,” https://portal.census.gov/pulse/data/. 


\section{Appendix A: Supplementary Table}

\begin{tabular}{|c|c|c|c|c|c|}
\hline \multirow[b]{4}{*}{ Business Type } & \multicolumn{2}{|l|}{ Percent } & \multicolumn{3}{|c|}{ Percent } \\
\hline & Change & Taxable & & Change & Taxable \\
\hline & $2019 Q 2$ to & Transactions & & $2019 Q 2$ to & Transactions \\
\hline & $2020 Q 2$ & Amount & Business Type & $2020 Q 2$ & Amount \\
\hline Total All Outlets & -17 & $152,362,296,481$ & Miscellaneous Store Retailers & -17 & $4,418,659,674$ \\
\hline \multirow[t]{2}{*}{ Total Retail and Food Services } & -17 & $105,528,311,167$ & Florists & -39 & $103,717,354$ \\
\hline & & & Office Supplies and Stationery Stores & -22 & $642,964,260$ \\
\hline Motor Vehicle and Parts Dealers & -15 & $19,294,245,937$ & Gift, Novelty, and Souvenir Stores & -58 & $197,790,991$ \\
\hline New Car Dealers & -16 & $13,661,226,032$ & Used Merchandise Stores & -44 & $144,130,178$ \\
\hline Used Car Dealers & -27 & $2,017,580,937$ & Other Miscellaneous Store Retailers & -8 & $3,330,056,891$ \\
\hline Other Motor Vehicle Dealers & 11 & $1,546,237,177$ & Nonstore Retailers & 181 & $13,273,550,077$ \\
\hline Automotive Parts, Access. and Tires & -3 & $2,069,201,791$ & Food Services and Drinking Places & -47 & $11,991,170,465$ \\
\hline Furniture and Home Furn. Stores & -18 & $2,625,229,637$ & Special Food Services & -76 & $292,967,418$ \\
\hline Furniture Stores & -28 & $1,532,455,251$ & Drinking Places (Alcoholic Beverages) & -86 & $65,185,094$ \\
\hline Home Furnishings Stores & 3 & $1,092,774,386$ & Full-Service Restaurants & -61 & $4,454,731,382$ \\
\hline Electronics and Appliance Stores & -14 & $3,663,719,124$ & Limited-Service Eating Places & -25 & $7,178,286,571$ \\
\hline Building Material and Garden Equipme & 12 & $12,248,068,380$ & Total All Other Outlets & -19 & $46,833,985,314$ \\
\hline Building Material and Supplies Dealı & 13 & $11,064,090,950$ & Agriculture, Forestry, Fishing and Hunting & 40 & $325,549,091$ \\
\hline Lawn and Garden Equipment and Su & 7 & $1,183,977,430$ & Mining, Quarrying, and Oil and Gas Extraction & -29 & $139,003,233$ \\
\hline Food and Beverage Stores & 2 & $7,584,295,812$ & Utilities & 0 & $364,305,709$ \\
\hline Supermarkets and Other Grocery Stc & 5 & $5,209,119,995$ & Construction & -17 & $2,305,307,376$ \\
\hline Convenience Stores & -12 & $841,092,239$ & Manufacturing & -13 & $11,005,456,107$ \\
\hline Specialty Food Stores & -40 & $202,729,466$ & Wholesale Trade & -17 & $18,392,665,466$ \\
\hline Beer, Wine, and Liquor Stores & 10 & $1,331,354,112$ & Transportation and Warehousing & -40 & $408,491,412$ \\
\hline Health and Personal Care Stores & -11 & $3,414,123,225$ & Information & -9 & $1,960,180,852$ \\
\hline Pharmacies and Drug Stores & 7 & $2,024,226,564$ & Finance and Insurance & -6 & $340,123,180$ \\
\hline Other Health and Personal Care Stor & -28 & $1,389,896,661$ & Real Estate and Rental and Leasing & -19 & $5,872,138,743$ \\
\hline Gasoline Stations & -47 & $7,737,896,946$ & Professional, Scientific, and Technical Service & 0 & $1,893,493,925$ \\
\hline Clothing and Clothing Access. Stores & -54 & $4,744,372,982$ & Management of Companies and Enterprises & -18 & $6,432,654$ \\
\hline Clothing Stores & -56 & $3,640,766,921$ & Administrative and Support and Waste Man. i & -39 & $597,633,328$ \\
\hline Shoe Stores & -38 & $648,398,066$ & Educational Services & -47 & $163,539,655$ \\
\hline Jewelry, Luggage, and Leather Good & -61 & $455,207,995$ & Health Care and Social Assistance & -15 & $286,043,742$ \\
\hline Sporting Goods, Hobby, Mus. Inst., Boo & -20 & $2,010,965,666$ & Arts, Entertainment, and Recreation & -83 & $188,119,522$ \\
\hline Sporting Goods Stores & 0 & $1,257,390,598$ & Accommodation & -92 & $94,715,762$ \\
\hline Hobby, Toy and Musical Instrument: & -30 & $553,514,156$ & Other Services (except Public Administration & -31 & $2,145,100,206$ \\
\hline Book Stores and News Dealers & -55 & $200,060,912$ & Public Administration & -11 & $103,363,587$ \\
\hline General Merchandise Stores & -10 & $12,522,013,242$ & Others & 59 & $242,321,764$ \\
\hline
\end{tabular}




\section{Appendix B: Supplementary Figures}

Figure B1: Taxable Sales Losses by County for All Outlets, Weighted by Population

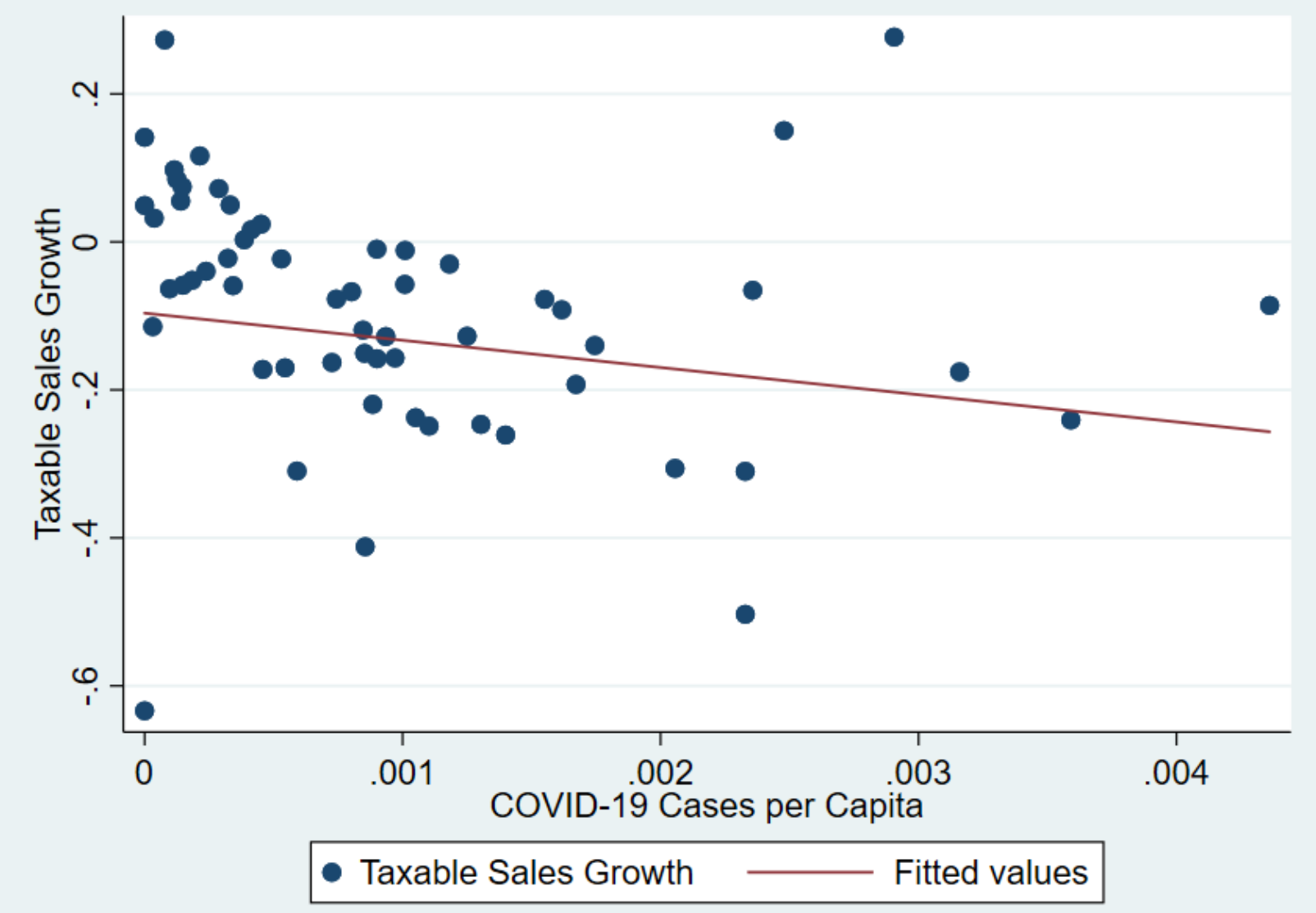

Notes: Each dot in the scatter plot represents one county in California. The taxable sales growth rate is the relative change between 2019 Q2 and 2020 Q2 for all outlets. COVID-19 cases are the cumulative confirmed cases per capita in the county by May 15th, 2020. A linear bivariate regression line, weighted by county population, is also shown. 
Figure B2: Taxable Sales Losses by County for Gasoline Stations

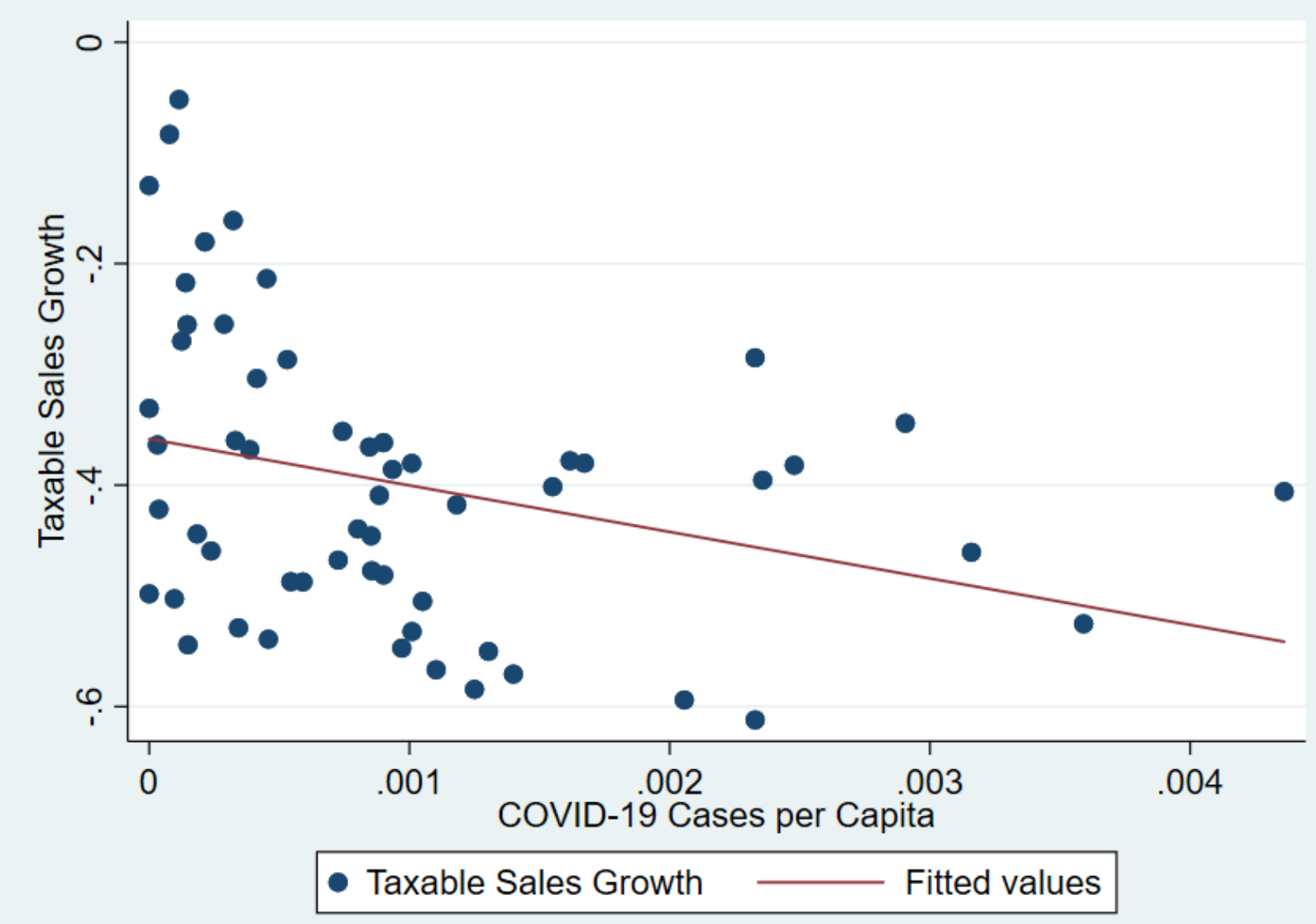

Notes: Each dot in the scatter plot represents one county in California. The taxable sales growth rate is the relative change between 2019 Q2 and 2020 Q2 for gasoline stations. COVID-19 cases are the cumulative confirmed cases per capita in the county by May 15th, 2020. A linear bivariate regression line, weighted by county population, is also shown. 